\title{
Понятие гипернигилизма: споры о современном нигилизме
}

Постановка проблемы. Проблема европейского нигилизма была поставлена Ф. Ницше. Именно он в работе "Воля к власти" впервые зафиксировал признаки перехода западного общества в состояние, определённое им как "процесс девальвации высших ценностей" [1, с. 31]. Позднее такие выдающиеся фрилософо, как Х. Ортега-и-Гассет, М. Хайдеггер, Э. Фромм, Х. Арендт, Ж.-П. Сартр, Г. Маркузе, Ж. Бодрийяр и др., фриксировали и исследовали данную ситуацию, обращая своё внимание на следствия тех процессов, которые созрели в западном обществе в кон. XIX - нач. XX вв., а с наступлением постмодерна сформировались окончательно. На сегодняшний день данная проблема продолжает существовать в качестве объекта внимания мирового философрского сообщества, равно как и информационного общества в целом. Одним из следствий этого внимания является концепция гипернигилизма, авторами которой являются Б. Стиглер и С. Зоргнер. Они, в свою очередь, дают полное обоснование того, что современный мир имеет тенденцию приближения к ситуации гипернигилизма - превращённой фрормы нигилизма, соответствующей реалиям информационного общества. Однако существует и обратная точка зрения: в современном мире нигилизм более не существует или даже само это понятие - не более, чем социокультурный конструкт. Утверждается, что современный человек стал уделять больше внимания ценностному плану своего бытия, приписывать ценностям смысл, а порой и сакральность. Данный тезис выразил в своей работе [8] нидерландский исследователь, видный ницшевед Пауль ван Тонгерен. В әтой связи целью нашей работы является обоснование современной формы нигилизма как гипернигилизма; для достижения данной цели нам необходим анализ концепций теоретиков гипернигилизма - Б. Стиглера и С. Зоргнера а также концепции П. ван Тонгерена в качестве оппонирующей стороны. Однако перед этим следует вспомнить, что представлял собой нигилизм в понимании Ф. Ницше.

Нигилизм. Нигилизм начал созревать в духе истории Западной цивилизации кон. XIX - нач. XX в. в социально-экономическом аспекте. Западный человек указанной эпохи, несмотря на прогрессивизм своих намерений и действий, утратил ценностную почву своей жизни, что стало оборотной стороной таких явлений, как научно-технический прогресс, бурный экономический рост, империализм. Явление было зафиксировано Ф. Нищше, который стал своего рода пророком начала конца Запада. Мы полагаем, что состояние нигилизма обнаружило два значимых симптома, которыми являются социокультурная атомизация и восстание масс.

Под социокультурной атомизацией мы подразумеваем феномен переориентации субъектов с приоритета связей личностного характера на приоритет связей безличного характера, ориентированных на индивидуальную успешность [3, с. 192]. Дефиниция термина "Восстание масс" предложена, как известно, Х. Ортегой-и-Гассетом. В своей работе "Восстание масс" он постулирует мысль, что масса - это всякий и каждый, кто ни в добре, ни в зле не мерит себя особой мерой, а ощущает таким же, как и все, и доволен неотличимостью от других $[\mathbf{4}, \mathbf{c . ~ 4 5 - 4 6 ]}$. Более того, масса всегда плывёт по течению и лишена ориентиров [4, с. 67]. В аспекте этих двух симптомов нигилистического кризиса представляется интересным проследить явления нигилизма и гипернигилизма.

КОРОБЕЙНИКОВ Вадим Сергеевич, студент Дальневосточного федерального университета (2. Владивосток). E-mail: korobeinikov.vs@students.dvfu.ru 
Как отмечалось выше, главной работой Ф. Ницше в отношении осмысления нигилизма, является "Воля к власти". Согласно Нищше, нигилизм как таковой есть процесс девальвации высших ценностей. Сам нигилизм радикализируется тем, что сознание субъекта не способно выстраивать свою жизнь вне христианской морали, вследствие чего субъект более не способен разделять высшие ценности и бороться за них [1, с. 31]. Таким образом, высшие ценности оказались обесцененными, ибо выяснился низменный источник этих ценностей. Однако это только переходное состояние $[1$, с. 32]. Далее немецкий мыслитель концептуализирует стадии развития нигилизма:

В результате поиска в реальности "смысла", которого в ней нет, ищущий в конце концов падает духом. Человек тонет в разочаровании $[\mathbf{1 ,}$ с. 33].

Человек жаждет логоса, но теперь и логос не "логосен", он тотальный хаос $[1$, c. 34]. После первой стадии человек обесценивает себя и свои моральные максимы через раскрытие тотального ничто в своём бытии, мышлении и в социально-экономической жизни в целом.

Поиск метафизичности мира оборачивается полным отрицанием метафоизики через неверие в неё [1, с. 35]. Конечной стадией, согласно Ф. Ницше, является полная эрозия принципов и основоположений устройства мира в целом. Следовательно, метафизика (первая фрилософия) не имеет в себе никакой ценности и в итоге превращается в пустой конструкт.

Данный процесс оборачивается тем, что человек попросту ограничивается самим собой, однако в ситуации обесценивания всех ценностей это приносит лишь новые разочарования. Включается процесс атомизации человека, проявление его отчужденности от мира и от самого себя. В связи с этим нет смысла говорить об отражении себя в Другом и тем самым о познании себя через Другого, и внутренний мир таких людей заполняет дурная пустота.

Однако всё ли так плохо с западным человеком? Нигилизм трагичен, но одновременно он является состоянием сильных умов и воль [1, с. 39]. Сама смелость, готовность к невероятному новому, порыв "нет" способен пробуждать в субъекте новые смыслы. Если его "Я" говорит "нет", следовательно, оно существует, и появляется горизонт, отрицающий бессмысленность мира. Таким образом, нигилизм подразумевает наличие в субъекте мужество быть и побуждает его на поиск новых максим, которые обещают новую, осмысленную жизнь через разрушение нынешней бессмыслицы. Гуманизм такого человека атрибутирован войной против ложных идеалов. Данный вызов есть ни что иное, как экзистирование человека. Таким образом, человек способен преодолеть атомизацию, выйти за рамки тотального ничто. Перед ним возникают вечное становление, возвращение к человеческому в самом человеке через постоянное экзистенщиальное расширение границ своего мира.

Таким образом, нигилизм расслаивает общество, порождая противоположные типы людей - сверхчеловека и последнего человека. Первый пользуется нигилизмом как поводом для возвращения себе человеческого путём бесконечного самопреодоления, второй сужает космос до собственной потребительской мелочности.

Гипернигилизм. Под гипернигилизмом Э. Вудварт предлагает понимать ситуацию обесценивания ценностей под воздействием синтеза цифровых технологий (или биологических данностей) и капитализма в сфере разума в информащионную эпоху [8, p. 256]. Речь идёт о переосмыслении ницшеанского понимания нигилизма. Теоретики гипернигилизма, оценивая ситуацию в современном мире, исходят из разных точек зрения. В частности, моментом расхождения Б. Стиглера и С. Зоргнера выступает трансгуманизм. Опасения Б. Стиглера связаны с последствиями информационных технологий, "технизацией" непосредственно самого разума, а не тела $[8$, p. 256]. Он ссылается на Ф. Ницше, утверждая, что трансгуманизм является апофеозом сегодняшнего нигилизма.

Французский философ и антрополог Бернар Стиглер акцентирует внимание на том, что нигилизм $\Phi$. Ницше может быть интерпретирован с точки зрения появления информационных технологий в сочетании с капитализмом. По его словам, "разве не удивительно наблюдать, насколько актуальны соображения Ф. Ницше в эпоху алгоритмической государственности и big data?" [9, p. 257]. И не только цифровизация начинает доминировать над человеком. Современный капитализм взращивает автоматическую расчетную раци- 
ональность через алгоритмы информационных технологий для всё большего превращения субъекта в потребителя. Атомизация в ситуации гипернигилизма разворачивается постольку, поскольку над человеком нависает новый тотальный суверен в лице цифровых технологий, который не может быть отвергнут. Технологии внедряются в рациональную составляющую человека и вместе с капитализмом выстраивают систему, при которой только алгоритмическая точность способна управлять разумом субъекта, внедряясь в него через капиталистические отношения и тотальную коммуникацию.

Согласно Б. Стиглеру, данный процесс происходит в результате экзосоматизации, в результате которой техническое начинает доминировать в самом теле человека. В результате соединения биологических и технических процессов в человеке возникает ситуация энтропии, которая нивелирует способность субъекта к экзистированию. Преданный власти техники, он, таким образом в новых условиях вновь встречается со старой проблемой атомизации. Уменьшение объёма желаний приводит к немедленному, но краткосрочному их удовлетворению, тем самым подрывая способность субъекта проецировать значимые долгосрочные цели [9, p. 257]. Субъект вновь отдаляется от осмысленности саморазвития и самопреодоления, приходя в конечном счёте к ситуации бессмысленности. Субъект погружается в поток быстро сменяющих друг друга мелких желаний. Таким образом, смысл жизни субъекта предопределяет не он сам, а цифровые технологии, которые к тому же фрормируют и упаковывают мелкие ценности, вручая их субъекту готовыми для употребления. Суженый до этой мелкости космос вновь делается маленьким.

Капитализм вступает в синтез с технологиями, используя их возможности для манипулирования "маленьким" человеком, и пренебрегая тем, что своими действиями обесценивает жизненный мир последнего. Место ценностей занимают впечатления, возникает цифровая экономика впечатлений, которая и приводит к ситуации гипернигилизма.

В этой ситуации Б. Стиглер настаивает на необходимости валоризации (переоценки) социальных структур и институтов, которые на данный момент радикально подорваны энтропийными силами промышленного потребительского капитализма. Преодоление данной ситуации возможно лишь тогда, когда цифровой капитализм будет признан антигуманным [9, p. 258].

Стедан Лоренц Зоргнер исходит из иных предпосылок. В отличие от Б. Стиглера, он видит много общего между идеями Ф. Нищше и идеями трансгуманизма, считая $\Phi$. Нищше первым его представителем [9, p. 254]. Согласно С. Зоргнеру, немецкий мыслитель полагает существование людей в качестве "психофизиологических квантов", погружённых в собственный мир [9, p. 254], артикулируя тем самым подчёркнутую нами атомизацию. Атомизация же делает человека ограниченным и склонным к обесцениванию ценностей.

Это усугубляется тем, что капитализм сегодня способен манипулировать желаниями, вызывать те или иные импульсы в самих "квантах". Субъект попадает в сильную зависимость и в итоге утрачивает саму человечность [9, p. 254]. Природа сама по себе лишена ценностей и привлекается в качестве "союзницы" современного капитализма, поскольку это солидаризирует её с капиталистической логикой потребления, минимизирующей ценности. Место вечных, неизменных ценностей занимают сиюминутные, маленькие желания, регламентирующие социальное взаимодействие. Существо, которое звалось Человеком, становится "последним" субъектом информационного общества. В итоге формируется ситуация гипернигилизма.

Несмотря на констатацию состояния гипернигилизма, С. Зоргнер утверждает, человек в итоге способен развиваться и эволюционировать, если человеческий вид не прекратит свое существование. Это оптимистически утверждается трансгуманистами [7, p. 30] и тем самым, на наш взгляд, вновь открывает дорогу к атомизации. Поэтому трансгуманизм скорее противоречит позиции Ницше, поскольку, согласно последнему, у каждого человека, в зависимости от жизненного опыта и мировоззрения, есть уникальное понимание "того, в чем состояло бы его собственное совершенство" [7, p. 34]. А это уже отличает его от позиции "психофизиологического кванта".

$\mathrm{C}$ другой стороны, понятие ницшеанского сверхчеловека является схожим с понятием трансчеловека. Трансчеловек - это некто, активно готовящийся стать постчеловеком; достаточно информированный, чтобы увидеть в 
будущем новые возможности. Он готовится к ним и использует все существующие возможности для самоулучшения $[6$, p. 513]. Постчеловек - это гипотетическое существо из будущего, чьи основные способности настолько сильно превышают возможности нынешних людей, что уже не могут быть однозначно человечными по нашим нынешним стандартам. Он - конечная фраза человечества [5, p. 5]. Сверхчеловек - это "транзитный человек", который на основе технологий, культурных ценностей и образа жизни составляет эволюционную связь с новым типом человечества $[7$, p. 36]. У индивидуальных членов вида людей есть способность развить только определенные ограниченные качества. Учитывая определенные условия, которые не фиксируются Нищше, развитие человека имеет место в индивидуальном плане. Эволюция представляет собой скорее скачкообразное, а не пошаговое развитие от одного вида к другому [7, p. 37-38].

Таким образом, сверхчеловек Зоргнера является субъектом, который способен превзойти себя, стать больше на основе технологий и научный знаний [7, p. 41]. Улучшение жизни, усовершенствование и расширение технологических возможностей в человеке, благодаря которым всё природное в человеке устраняется (в целях разрыва связи с манипулированием желаниями со стороны капитализма), - всё это преодолевает атомизацию и восстание масс. Вечное "транс-становление" благодаря техническим возможностям должно помочь последующему человеческому виду выйти на новый виток эволющии. "Последний" человек, наоборот, превращается в исчезающий вид, тупиковую ветвь эволюции.

В результате анализа гипернигилизма Б. Стиглера и С. Зоргнера мы пришли к следующему:

Гипернигилизм, согласно Б. Стиглеру, есть ситуация, при которой обесцениваются ценности путём вторжения в разум технологий. Они в свою очередь управляются капитализмом.

Гипернигилизм, согласно С. Зоргнеру, есть ситуация, при которой обесцениваются ценности через доминирование природы в человеке в синтезе с капитализмом.

Сверхчеловек, согласно Б. Стиглеру, является субъектом, который благодаря валоризации энтропии способен преодолеть в себе сверхрационализированную ипостась, которой управляет машина.

"Последний" человек, согласно Б. Стиглеру, является субъектом, который через экзосоматизацию стал заложником информационных технологий, благодаря которым капитализм управляет им и продаёт не большие идеи, а краткосрочные впечатления.

Сверхчеловек, согласно С. Зоргнеру является индивидом, способным в себе преодолеть биологическое начало, которое находится в тесном синтезе с капитализмом. Такое преодоление возможно только благодаря технологиям, которые являются инструментом спасения человека. Разум подчиняет себе технологии априори, поэтому техника не способна себе подчинить человека.

"Последний" человек, согласно С. Зоргнеру, является субъектом, который полностью подчиняется биологическим процессам. Он - психофизиологический квант, управляемый капитализмом. Он обречён на вымирание как биологического вида.

Несмотря на видимый антиномизм между позищией Б. Стиглера и C. Зоргнера, мы считаем, что их стоит принять в равной степени, так как расхождение их позиций говорит о вариативности сценариев развития гипернигилизма в наши дни.

В целом общий философрский уровень вышеозначенных концепций гипернигилизма позволяет охарактеризовать как достаточно перспективные в ряду подходов, претендующих на осмысление проблем современного мира.

Позиция нидерландского философа П. ван Тонгерена. Нидерландский историк философии Пауль ван Тонгерен в своей работе "Friedrich Nietzsche and European Nihilism" [8] пытается осмыслить сущность нигилизма применительно к современности. Он пишет, что нигилизм сложно сегодня представить, употребление этого понятия парадоксально. Стоит ли нам бояться наступления "нигилизма"? [8, p. 140]. Как отмечает исследователь, если бы мы переживали по поводу наступления нигилизма сегодня, мы бы тем самым доказали, что ещё не избавили себя от старых ценностей, которые, 
по словам Ф. Нищше, были в своё время обесценены. Если мы выражаем своё беспокойство об исчезновении ценностей, значит мы всё ещё живём среди них, ибо они для нас всё ещё имеют место быть. Мы сохраняем их, пытаемся защитить от нигилизма. Также, если кто-то утверждает, что вера в Бога или осознание фундаментальной разницы между добром и злом исчезает, не осознаёт того, что он даёт оценку ценностям, следовательно, всё ещё привязан к ним $[8$, p. 141]. Стадии нигилизма современный человек, как в случае человека эпохи Ф. Ницше, банально не проходит. "Жизнь каждого из нас всё ещё имеет смысл. Мы можем за ценности постоять" - таков тезис ван Тонгерена.

П. ван Тонгерен отмечает, что люди, которые жалуются на наступление нигилизма, сами по себе продолжают жить в мире, который не становится нигилистичным. В лучшем случае они наблюдают то, что другие сбились с пути поиска смыслов. Однако сами они знают, что "Бог не умер". Неважно, насколько тяжело людям даётся поиск ценностей. Поиск может быть трудным, и отсутствие результатов является печальным. Но знание о таком пути существует. Это наполняет действия человека значимостью, что противоречит поведению нигилистичного субъекта $[8$, p. 140]. Эту мысль можно резюмировать следующим образом: ценность поиска смысла в самом поиске.

Но как искать то, чего мы пока что не обнаружили? Разве это не должно нам говорить о сосредоточии последнего нигилизма: в осознании того, что нечего искать? Если нигилизма не существует как может ли это быть угрозой, которая зловеще маячит? [8, p. 140]. В связи с данной постановкой проблемы, ван Тонгерен выдвигает оригинальный тезис, который гласит, что нигилизм больше похож на спасение, чем на угрозу $[8$, p. 141]. То есть, ощущая, что в рамках цивилизации созревает "нигилизм", мы начинаем подготовку к встрече с ним. Люди не столько ожидают нищшеанской смерти Бога, сколько спасают себя от обесценивания ценностей. Таким образом, человек, принимающий нигилизм как угрозу, не был достаточно глубоко погружён в нигилизм.

Данный парадокс обнаруживается в словах М. Хайдеггера. Как отмечает П. ван Тонгерен, немецкий мыслитель писал о нигилизме как о забвении бытия. Это даёт нам понять, что мы поддаемся забвению самого нигилизма. Поэтому срочность нашей ситуации заключается в том, насколько нам не хватает чувства срочности. Дж. Ваттимо, итальянский современный фрилоcod, подчеркивает иную сторону тезиса. Он интерпретирует гибель или ослабление истины как истинный смысл евангельской правдивости. Но в обоих случаях нигилизм, скорее всего, исчез. В случае с М. Хайдеггером он вырос настолько, что мы его не можем осознать. В случае с Дж. Ваттимо нигилизм превратился в обнадеживающее обещание [8, p. 141].

Нигилизм, по Тонгерену, есть исторический концепт эпохи Нищше. Сегодняшний субъект куда менее склонен обесценивать ценности, чем в его время. Более того, сама оценка наличия нигилизма означает, что мы данному френомену приписываем ценность (в том смысле, что мы ему можем предписать, охарактеризовать негативными характеристиками). Мы о-цениваем нигилизм.

Таким образом, Пауль ван Тонгерен в своём исследовании формулирует следующие тезисы:

Мы не можем считать, что нигилизм сегодня существует, потому что сегодняшний субъект в большей степени отстаивает ценности и смыслы, которые обесценивались во времена Ницше, и находится в их поиске.

Говорить о нигилизме сегодня представляется нерелевантным, поскольку тот, кто до сих пор принимает нигилизм как угрозу, не был достаточно глубоко погружён в суть этого понятия.

Критика позиции П. ван Тонгерена с позиций гипернигилизма. Как следует оценить тезисы П. ван Тонгерена? Представляется, что нидерландский исследователь в своём рассуждении, к сожалению, не учитывает тот экономический фрактор, на который указывают теоретики гипернигилизма: связь капитализма с технологиями и с природой. Не учитывается, что при наличии детерминации со стороны "больших данных" (или природы) в союзе с капитализмом, современному субъекту всё труднее подвергать самостоятельному осмыслению окружающий мир и формировать ценностные ориентации. Конечно, имелся бы смысл говорить об искренности, о гуманизме в современном мире, однако данное обстоятельство говорит о противоположных вещах. 
Субъект ныне является своего рода "желающей пустотой", надеется и ищет сакральное, божественное в ницшеанском смысле или даже пытается стать Сверхчеловеком, оставаясь тотально детерминированным нынешним капитализмом. Поэтому говорить о наличии ценностей сегодня приходится, но с большой опаской.

Важно заметить спорность идеи поиска смысла в самом этом поиске. Представляется, что ван Тонгерен здесь снова не учитывает всю мощь и силу нынешнего капитализма. Да, мы можем полагать, что наличие поиска ценностей само по себе ценно. Но лишь в том случае, если этот поиск не детерминирован природой или техникой. Формирование капитализмом миров краткосрочных желаний выстраивает хаотические цепи псевдоценностей: не мы для себя определяем, что для нас является значимым, ценным, но внешняя система декларирует нам принципы, коих стоит придерживаться в краткосрочной перспективе. В такой ситуации поиск становится обесцененным. Субъект, находясь в тотальном подчинении сверхрациональности (или биологического естества) и при этом являясь "марионеткой" капиталистической системы, всё менее способен осмыслить данный процесс и понять, что он духовном плане погружён в гипернигилизм, ибо теряет способность к осмыслению.

Таким образом, оптимизм П. ван Тонгерена представляется нам преждевременным. Наоборот, сегодня фриксируется созревание нигилизма, но в превращённой форме - в форме гипернигилизма, сопровождаемого развитием информационных технологий и усиление внимания к биологической природе человека, т. е. процессами, используемыми современным капитализмом.

Заключение. В ходе исследования мы пришли к следующим выводам:

$\Phi$. Ницше указал на сущность нигилизма, которая заключается в утрате индивидом себя через утрату смыслополагания. Он открыл то, каким образом человек впадает в данное состояние по фазам; отрицание нигилизма также болезненно, ибо это не даёт человеку принять кризис цивилизации.

Специфика концепта гипернигилизма обусловлена современным состоянием капитализма, который способен манипулировать человеком при помощи технологий или изменений в его биологической природе. У Б. Стиглера и у С. Зоргнера концепции гипернигилизма различаются (подробнее см. выше).

3) Согласно П. ван Тонгерену, нигилизм сегодня не существует, поскольку субъект сегодня скорее отстаивает, чем ничтожит те ценности и смыслы, которые обесценивались во времена Ницше.

4) Позиция ван Тонгерена может быть подвергнута критике в силу высокой зависимости современного субъекта от технологий и биологического вмешательства в его природу.

\section{Литература}

1. Ницше, Ф. Воля к власти. Опыт переоценки всех ценностей: [пер. с нем.] / Ф. Ницше. М.: Культурная Револющия, 2005. $880 \mathrm{c.}$

2. Ницше, Ф. Так говорил Заратустра. Книга для всех и ни для кого: [пер. с нем.] / Ф. Ницше. М.: Культурная Революция, 2007. 432 с.

3. Новиков, А. С. Атомизация общества и её роль в становлении "общества масс" / А. С. Новиков // Теория и история. 2009. № 2 (16). С. 192-197.

4. Ортега-и-Гассет Х. Восстание масс // Избранные труды / Х. Ортега-и-Гассет. М.: Весь мир, 2000. 704 с.

5. Bostrom, N. The Transhumanist FAQ. A General Introduction / The World Transhumanist Association. Oxford University, 2003. 54 p.

6. More, M. Vita-More, N. The Transhumanist Reader: Classical and Contemporary Essays on the Science, Technology, and Philosophy of the Human Future / John Wiley \& Sons, 2013. $561 \mathrm{p}$.

7. Sorgner, S. L.11 Nietzsche, the overhuman, and transhumanism [Электронный pecypc] // Journal of Evolution and Technology. 2009. Vol. 20. Issue 1. P. 29-42. URL: http://jetpress.org/v20/sorgner.htm (дата обращения: 01.04.2021).

8. Tongeren, van Paul. Friedrich Nietzsche and European Nihilism / Cambridge Scholars Publishing, 2018. 208 p.

9. Woodward, A. Nihilism, Neonihilism, Hypernihilism: 'Nietzsche aujourd'hui' Today? // Nietzsche-Studien: Internationales Jahrbuch für die Nietzsche-Forschung. 2019. 48 (1). PP. 244-264. 


\section{Транслитерация по ГОСТ 7.79-2000 система Б}

1. Nitsshe, F. Volya k vlasti. Opyt pereotsenki vsekh tsennostej: [per. s nem.] / F. Nitsshe. M.: Kul'turnaya Revolyutsiya, 2005. $880 \mathrm{~s}$.

2. Nitsshe, F. Tak govoril Zaratustra. Kniga dlya vsekh i ni dlya kogo: [per. s nem.] / F. Nitsshe. M.: Kul'turnaya Revolyutsiya, 2007. 432 s.

3. Novikov, A. S. Atomizatsiya obshhestva i eyo rol'v stanovlenii "obshhestva mass" / A. S. Novikov // Teoriya i istoriya. 2009. № 2 (16). S. 192-197.

4. Ortega-i-Gasset KH. Vosstanie mass // Izbrannye trudy / KH. Ortega-i-Gasset. M.: Ves' mir, 2000.704 s.

5. Bostrom, N. The Transhumanist FAQ. A General Introduction / The World Transhumanist Association. Oxford University, 2003. $54 \mathrm{p}$.

6. More, M. Vita-More, N. The Transhumanist Reader: Classical and Contemporary Essays on the Science, Technology, and Philosophy of the Human Future / John Wiley \& Sons, 2013. $561 \mathrm{p}$.

7. Sorgner, S. L.11 Nietzsche, the overhuman, and transhumanism [EHlektronnyj resurs] // Journal of Evolution and Technology. 2009. Vol. 20. Issue 1. P. 29-42. URL: http://jetpress.org/v20/sorgner.htm (data obrashheniya: 01.04.2021).

8. Tongeren, van Paul. Friedrich Nietzsche and European Nihilism / Cambridge Scholars Publishing, 2018. 208 p.

9. Woodward, A. Nihilism, Neonihilism, Hypernihilism: 'Nietzsche aujourd'hui' Today? // Nietzsche-Studien: Internationales Jahrbuch für die Nietzsche-Forschung. 2019. 48 (1). PP. 244-264.

Коробейников В. С. Понятие гипернигилизма: споры о современном нигилизме.

В данной статье автором рассматривается позиция нидерландского историка фрилософии Пауля ван Тонгерена, который подвергает сомнению существование в наши дни явления нигилизма в ницшеанском смысле этого слова. Согласно ван Тонгерену, нигилизм сегодня не существует, поскольку субъект сегодня скорее отстаивает, чем ничтожит те ценности и смыслы, которые обесценивались во времена Ф. Ницше. Однако не все разделяют данный тезис. Теоретики гипернигилизма Б. Стиглер и С. Зоргнер обосновывают свои позиции, переосмысляя концепцию нигилизма и сверхчеловека Ф. Ницше.

Ключевые слова: нигилизл, гипернигилизл, Западная иивилизация, Сверхчеловек, П. ван Тонгерен, Ф. Ницше, Б. Стиглер, С. Зоргнер nihilism.

Korobejnikov V.S. The notion of hypernihilism: the debate over modern

This article examines the position of the Dutch historian of philosophy Paul van Tongeren, who questions the existence of the phenomenon of nihilism in the Nietzschean sense of the word these days. According to van Tongeren, nihilism does not exist today because the subject today defends rather than nullifies the values and meanings that were devalued in Nietzsche's time. However, not everyone shares this thesis. The theorists of hypernihilism B. Stigler and S. Zorgner justify their positions by rethinking Nietzsche's concept of nihilism and the Overhuman.

Key words: nihilism, hypernihilism, Western civilisation, Overhuman, P. van Tongeren, F. Nietzsche, B. Stiegler, S. Sorgner

Для цитирования: Коробейников В. С. Понятие гипернигилизма: споры о современном нигилизме // Ойкумена. Регионоведческие исследования. 2021. № 4. С. $123-129$. DOI: $10.24866 / 1998-6785 / 2021-4 / 123-129$

For citation: Korobejnikov V. S. The notion of hypernihilism: the debate over modern nihilism // Ojkumena. Regional researches. 2020. № 1. P. 123-129. DOI: 10.24866/1998-6785/2021-4/123129 